$\xi=-$ 国

\title{
Theories, Techniques, Methods and Approaches of Second Language Acquisition: a Psychological Perspective
}

\author{
A. Delbio ${ }^{1 *}$, M. Ilankumaran ${ }^{2}$ \\ ${ }^{1}$ Research Scholar, Department Of English, Noorul Islam Center For Higher Education, Kumaracoi, Kanyakumari District, Tamil Nadu, \\ India. \\ ${ }^{2}$ Professor, Department Of English, Noorul Islam Center For Higher Education, Kumaracoi, Kanyakumari District, Tamil Nadu, India. \\ *Corresponding Author E-Mail:Delbiodel@Gmail.Com
}

\begin{abstract}
Psychological aspects play an important role in language learning. Motivation is one of the terms used to achieve the language. The theories of second language focus mainly on motivation, nature of motivation, implications of second language acquisition and linguistic process. The theories are practices and used as a teaching method. The instructor can have a clear vision on theories to implement them in the classroom. The learning environment and reinforcement are the important factors in learning psychology. Due to psychological problems and lack of training and guidance, the learners lose hope of learning. Cognitive psychology deals with mental process which involves in language learning. This paper aims at analysing the psychological factors affecting language acquisition and analyses the psychological theories, techniques, methods and approaches to develop the language acquisition.
\end{abstract}

Keywords: Psychological factors, theories, techniques, methods, approaches, dysgraphia, pervasive, dysprosody, cognitive, socio factors.

\section{Introduction}

In this globalization, English language serves the students with great deal. The language inter connects the world and provides job opportunities in the global economy. That is why, English language is considered an international language. "International trade, diplomacy and scientific technological area of expertise. They have to be innovative and contribute to the knowledgebased of the word. In order to achieve these goals, they need to be able to utilize the most widely used medium, English" (Kachru and Smith, 1501). According to him, English is the wide spread language in the world. Human psychology plays a significant role in learning situation and environment. The need of the perspective teacher is to understand the systematic development of psychology. The teacher has to study the behaviour of learners from different approaches. The teacher can take advantage in effective changes in learners, based on psychological systems.

\section{Psychological Theories of Second Language Acquisition}

A number of theories is there to develop the second language. Seven theoretical models give the clear idea of individual difference in second language acquisition. These theories are discussed in two sections.

\section{First Section of Theories}

First section has three theoretical models which focus on linguistic process and second section has four theoretical models focussing on social process. Acquisition of language involves in learning vocabulary, grammatical functions and pronunciation which involves in linguistic phenomenon.

The theory of Stephen Krashen's monitor model, Corroll's Reinforcement model and Bialystok's Strategy model deals with linguistic aspects.

\section{Stephen Krashen's the Monitor Model}

Stephen Krashen is specialized in the field of linguistics and in theories of language acquisition and development. Krashen's monitor model is a well known hypothesis which was developed in 1970s.

Education system adopted this model in 80 s and 90 s. The theory brings high weightage in the classrooms. Krashen believes that there is no fundamental relationship between acquiring the first language and target language.

He says everyone has the innate ability to acquire language learning process. Krashen identified monitor model theory for second language learning. The Monitor Model theory has five hypotheses.
1. The Acquisition-Learning Hypothesis
2. The Monitor Hypothesis
3. The Natural Hypothesis
4. The Input Hypothesis
5. The Affective Filter Hypothesis

\section{The Acquisition-Learning Hypothesis}

There are many theories in the field of linguistics to develop the language. Stephen Krashen's The Acquisition-Learning Hypothesis gives two ways in developing the linguistic skills which are the acquired system and the learned system. The acquired system is the subconscious process. It is like the children acquiring the first language. 
The learned system is the conscious process. In this process the children learn the language with grammar rules. Stephen Krashen gives more importance to acquisition than learning.

\section{The Monitor Hypothesis}

The Monitor Hypothesis brings the relationship between acquired system and learned system. The learned system performs as a monitor in the monitor hypothesis. The production of spontaneous over flow of speech comes only in acquired system. In the acquired system, learner needs to check their utterance with the help of learned system. The learners use the Monitor Hypothesis for self-correction. Self-monitoring and self-correction are the main functions of learning a language consciously.

\section{The Natural Hypothesis}

Natural Hypothesis is the acquisition of language with grammatical structure. This hypothesis can be used for both the first and the second language acquisition. Krashen says if the children who acquire English as a second language can also acquire morphemes. Kevin R. Gregg argues that the second language learners learn the features of morpheme in sequence. The first language influence is there in learning or acquiring the second language. In natural order hypothesis, the second language learners do not need to acquire grammar in sequence.

\section{The Input Hypothesis}

The input hypothesis gives the explanation of the way in which the learners acquire the second language. This hypothesis gives more concern about acquisition not on learning. This hypothesis advocates Natural hypothesis. In learning a second language 'input' takes place. The learner gets improved from his current stage of linguistics competence. Natural communicative input makes the learners improve the current stage of linguistics competence.

\section{The Affective Filter Hypothesis}

In the hypothesis, there are many affective variables in second language acquisition. Motivation, self-confidence and low anxiety are some of the affective variables in Affective Filter Hypothesis. Krashen states that the learners with high motivation, selfconfidence and low level of anxiety bring them a great success in second language acquisition. On the other side, learners with low motivation, self-confidence and high anxiety ends in affective filter. Positive reinforcement brings the learners a great success.

\section{Corroll's Conscious Reinforcement Model}

Carroll proposed a model under linguistic process model. Which is the one for language acquisition based on traditional learning theory and present day cognitive psychology. In this model, reinforcement is the major concept more than behavioural psychology. The individuals achieve their purpose automatically through cognitive involvement. Carroll's idea matches with that of Krashen regarding cognitive control. At the same time, Carroll did not distinguish between learning and acquisition.

\section{Bialystok's Strategy Model}

Bialystok's Strategy Model gives the detail of individual difference in language learning and skill development. This model discusses three levels. The levels are Input, Knowledge, and Output. Input involves in language learning through the exposure of formal classroom, reading material, and through communication. The exposure gives three types of knowledge. They are other knowledge, explicit linguistic knowledge and explicit linguistic knowledge. Other language means any kind of knowledge which relates to second language. Explicit linguistic knowledge deals with the conscious knowledge and the pronunciation and grammar of the language. Implicit linguistic knowledge refers to the intuitive knowledge about the language. The production of language is known as output which shares its link only with implicit linguistics knowledge. These are the characterization which gives the description of process involved in language acquisition.

Language learning strategy has four types. They are formal practising, functional practising, monitoring and interference. In the formal strategy, the individual gives attention to the rules of grammar, pronunciation, etc. This strategy makes a part of explicit language knowledge. In this instance, the individual mainly focuses on language form and they practice it regularly to get automatic output.

Functional practising is the second strategy which involves in increasing the language exposure to improve the communication. This strategy exposes the linguistic knowledge and tries to improve the language automatically. The individual can practise the target language by communicating and watching movies or programmes on target language. This strategy is compared with Krashen's concept of language acquisition.

Monitoring is the third strategy which concentrates more on language production. This strategy refers to explicit linguistic knowledge. Language gets modified in behaviour through learning the linguistic and grammar rules. This concept is similar to Krashen's theory of language learning. Interference strategy is the fourth type of language learning which deals with acquiring knowledge about the target language.

\section{Second Section of Theories}

Second section has four theories focussing on social models. An individual's social adjustment plays an important role in language acquisition. Language is acquired to facilitate communication, not worrying about active or passive with cultural community. Second language creates interest in learning new cultural community. The four theories are discussed below.

\section{Lamert's Social Psychological Model}

The Social Psychological Model is used in second language acquisition. It is the theory for the development of bilingual and self-identity modification. Lambert says that the central preposition of this theory is linguistic distinctive in a basic components of personal identity. The individual's self-identity is revealed in the process of second language acquisition. Lambert says students should be able and willingly adopt the second language behaviour. This model involves in both cognitive and affective components.

In second language acquisition, cognitive factors and affective factors are the main components. Cognitive factors deal with aptitude and intelligence. Affective factors deal with attitude and motivation. Lambert's theoretical model mainly focuses on the role of affective factors. The individual acquires the second language by depending upon ethnocentric trendencies, attitude and orientation towards language learning and motivation.

\section{Schumann's Acculturation Model}

Acculturation is the way of acquiring a new culture. The Acculturation model focuses on natural method. Schumann says that the instruction is not given and natural environmental setting is given in this model. He presents the factors influenced in the second language acquisition. He argues two types of factors involved in acquiring the language. The factors are social factor and affective factor. Normal people use to migrate from one place to another. In that situation they may adopt new culture. In 
acculturation process they may not lose their native culture. Motivation and attitude give much importance in this process.

\section{Clement's Social Context Model}

Social context models insist that the learners need to adopt the behaviour and ethic of second language along with language skills. Self-identity is learned in this model. The main concept of this model is motivation. Self-confidence is improved in this process.

\section{Ball And Giles Intergroup Model}

Intergroup theory is otherwise known as The Accommodation Theory. The main concept is to develop and maintain the selfimage. It is the major motivating force. This model tries to motivate the self-image. Ellis says that this model is appropriate in the classroom. Self-concept of the learner is given importance in this model.

\section{Techniques and Methods of Second Language Acquisition}

Pedagogically, there are some characterizations in teaching second language. Brown says "changing winds and shifting sands of language teaching"(Brown,1994).Many a research has found effective teaching methods and the way of teaching languages. Some of the methods are discussed in this paper.

\section{Grammar-Translation Method}

It is the oldest method of teaching English. It is one of the traditional approaches in language teaching. In this method, the English teachers will translate each and every word, phrase, and sentence into English from Mother Tongue. This method is used when the English language started in countries.

Grammar is given importance and Grammar rules are taught to the learners. Teaching of vocabulary is given importance. It is the teacher centred education. This method gives more importance to writing skill rather than speaking. Reading and writing is given importance. All the skills are not used properly.

\section{Bilingual Method}

In this method, grammar rules are not given importance. It is just translating the concepts from mother tongue to target language. In Bilingual method, two languages are used. In this method, the first language is allowed to use when it is needed. The unit of teaching is in sentence form. It gives a lot of practice in speaking English.

\section{Direct Method}

Direct method is a method of teaching a foreign language without the link of mother tongue. Direct method does not focus the structure of grammar. It gives importance to speaking skill. In this method English is taught by conversation. A lot of practice in hearing and speaking the language is imparted. The students are given phonetic knowledge. There is no use of mother tongue is the method. It gives importance to the unit of sentence and not the individual words. Grammar rules are taught inductively. Vocabulary is taught not by giving special care but it is given through speech activity. New words are taught with the help of objects or pictures. This method improves the pronunciation. Audio visual aids are used in order to give interest.

\section{Dr. Michael West's New Method (Reading Method)}

Dr. Michael West, the Director of education in Bengal, is a professor in Dacca University. He made a thorough study of various methods of teaching English. He found some disadvantage in the usage of Direct Method. He found that no method gives satisfaction. So he found a new method called 'The New Method of Teaching English'. The art of speaking and reading is interrelated. His method of teaching is based on psychological principles. This method is followed in Indian Schools. He gives importance to loud reading and silent reading. This method does not follow the formal Grammar teaching. This is reflected in his book 'How Much English Grammar'. Its aim is to develop the reading ability.

\section{Structural Approach}

The Structural Approach is first introduced in Chennai. Later it is widely used in India. The Government of India appointed Kunzru committee which was recommended by the U.G.C to conduct a conference for English teachers and Headmasters in 1958. In that conference, they approved structural Approach for language teaching. Structural Approach is not a method of teaching. This approach focuses on the question as what to teach in language. The teacher can use any method to teach the structures. Structural Approach is not a method but it is an Approach. Any method can be used to implement this approach. Structural Approach means arranging the words to form a correct sentence. Which is very important in English. The same word can be changed into question.

(e.g.) a) The post office is in front of the school.

b) Is the post office in front of the school?

The meaning of the sentence will get changed when the word is used differently.

(e.g.) a) The young man married the foolish girl.

b) The foolish man married the young girl.

The word ordered in English to be fixed. Change of word order result in change of meaning or sentences. This arrangement is called a Structure.

The principles of structural approach are giving importance to speech in learning language. A structure is taught in a meaningful situation. It gives Importance to pupil's activity and not the activity of teaching.

\section{Situational Approach}

Language is a product of situation and without appropriate situation there is no language with true sense. Our mind itself gets active only by situation. Pattison in his book, 'Modern Methods of Language Teaching' says at the main principles of language learning is contextualization. Every structure is practiced in situation. There are two kinds of situation. They are Real situation and Artificial situation.

\section{Real Situation}

To learn a foreign language, the learner may visit the area where it spoken. They may get a lot of real situations to learn the structure and vocabulary. In this process, learning becomes meaningful and purposeful.

\section{Artificial Situation}

In some cases, the real situation may not be possible. So the teacher can create the situation in classroom. This situation leads them to learn the structure and vocabulary. This is an artificial situation.

\section{The Oral Approach}

Another term of oral approach is Audio Lingual Method. This approach begins at the end of 1950s. It is originated in order to give more attention to foreign language. 
Under this approach, learners are assigned to pay attention to the recordings of language models. They practice various drills. Language lab is introduced and it is used as an important teaching aids. It avoids the use of mother tongue in the classrooms.

This approach has been summarised as:

a) Hearing before Speaking

b) Speaking before Reading

c) Reading before Writing

In this approach, the learner may imitate the pronunciation of the teacher. The Oral Approach brings the learner to understand the language quickly. Speech is considered as physical activity and it carried out in speech organs. This helps the pupil's fluency.

\section{The Communicative Approach}

A language is needed to communicate some functions like arguing, persuading and promising. A speaker can choose a particular way to express his intention. It is done through the interaction between the speaker and the learner. Structure and vocabulary are given importance for communication.

Target Language is used in communicative approach without banning Native Language. Communicative Approach advocates the use of authentic language materials like Newspaper article, radio or Television in order to avoid the problems. In this approach, the learners are given scrambled sentences to arrange in proper way. It is an active centred approach. This approach develops the fluency in speaking.

\section{Eclectic Approach}

There is no method is found perfect and acceptable. The teacher wants to choose the method on the base of classroom dynamic. The teacher should be aware of the method discussed before. The aim of the teacher should be to develop the English Language among the students by getting their skills focussed.

Oral practice techniques can be followed where a translation can be made use of where it is needed. Play-Way Method and Audio Visual aids are allowed to practice in the classroom.

\section{Audio Lingual Method}

Originally this method is called oral method. This method emerged at the end of 1950s. During this time foreign language was given great attention. Learner listen to the recording of language and models to get familiar with the language. The features of Audio lingual methods are

- Learnercan practice various drills in target language

- Language lab is introduced as an important teaching aid

- Learner use only the target language and not the mother tongue

- Dialogues are given importance

- It focuses on all the skills

\section{The Notional-Functional Syllabus}

It organises language learning as a curriculum than as the method or an approach. In notional-functional syllabus instruction was organised in Notions and Functions and not in the form of grammatical structure. The advocates of notional-functional syllabus say that there is shortage in audio lingual method in helping learner's development.

\section{Communicative Language Teaching (Clt)}

The CLT is also known as communicative approach Communicative language teaching highlights interaction method. This approach helps the learner to learn the meaning and not the grammar rules or pronunciation like native people. It focuses on how much the learners develop their communicative competence.
It the classroom, the CLT works in the form of pair work and the group work. The learner can be the active participant in the classroom. Communicative competence is a prime one. It also gives importance to fluency and accuracy.

\section{Total Physical Response (Tpr)}

This Language learning method was developed by Dr. James Asher. This method was linked with the trace theory of memory, more often memory is traced. Speech and action were given importance. Learners can do their best in doing the activity. Listening forms are the base of language learning. Meaning of the target language is conveyed through actions.

\section{Suggestopaedia}

Suggestopaedia is a teaching method which was developed by the Bulgarian psychotherapist GeorgiLozanov. It applies positive suggestion to teaching. Suggestopaedia is a term derived from 'Suggestion' and 'Pedagogy'. It is based on suggestology, it is a psychological theory which says human beings respond in a subtle way which they are not consciously aware of it.

The main principles of suggestopedia are,

Joy and psycho relaxation- learners use their hidden potential, when they feel relaxed and happy.

\section{The Silent Way}

This way develops the learners to become independent and responsible. The Silent Way of teaching learning was created by Caleb Gattegno. The teacher remains silent in the classroom and directs the way to improve the target language. This method gives importance to creativity and discovering activity.

\section{Community Language Learning (Cll)}

Community Language Learning is also known as Counselling Language Learning. The learner can work together and the teacher can act as a counsellor and paraphraser. The learners act as collaborators. This method was developed by Charles A. Curran, a specialist in counselling and psychology. It was created for adult learners who are in fear to overcome the difficulties. The teacher acts as a language counsellor to understand the learner and lead them to overcome their fear. It is based on Stephen Krashen's Monitor Theory and Cognitive Theory. Human mind need to be active. The teacher remains outside the circle of learners.

\section{Natural Approach}

The natural approach is developed by Tracy Terrell and it as supported by Stephen Krashen. It is a language teaching approach which acts as a reproduction of the way how human being acquires the native language. This approach follows the communicative approach to language teaching. This approach views communication is the primary function of language. Natural approach belongs to traditional approach of language acquisition. The naturalistic feature of first language acquisition is utilized in second language acquisition.

\section{Use Of E-Communication}

E- Communication is also a communication through electronics. This type of communication is called virtual space. This communication increases the speed of giving and receiving the information.

This technology supports the cognitive approach to learn a foreign language. This technology sorts the online activity to give interaction opportunity with in a class. E-Communication supports 
to exchange information in large distance. There is also a problem in E-Communication.

The problem is misunderstanding in conversation. Another problem in this technology is that the student use informal contractions and non-standard abbreviation in writing. In compare with formal teaching of a teacher, E- communication is given less preference.

Synchronous Communication like telephone or web conference can help the learner to achieve the activity at a particular time. Asynchronous communications like email texting and social media take different time to achieve the activity. There is no clear note that online technologies will give best solution for language learning.

If the learners do not involve themselves in learning, ECommunication will result in failure. This technology is time consuming one and hence it should be taken seriously.

\section{Computer Assisted Language Learning (Call)}

Computer Assisted Language Learning is another term of computer Mediated Language Learning. This learning has in two features. They are bidirectional learning and individualised learning. The CALL is not a method. It is a tool of learning. It is student centred learning. It was originated and developed in 1960s. Technology used in the CALL instruction falls into two categories. Software and Internet based activities. It acts as a learner and not as tutor. The reason of using the CALL includes experimental learning, motivation, enhance learner achievement, greater interaction, individualization and globalization. There are some barriers in practicing the CALL. The barriers are financial barrier, unavailability of computer hardware and software, lack of technological and theoretical knowledge and reluctance to accept technology.

\section{Psychological Perspectives of Second Language Acquisition}

The effects of environment, conditioning, reinforcement are the main assumption behind the learning psychology. Human behaviour is understood through these assumptions. Learning theories understand the process of learning and how it works. Major research traditions are behaviourism, cognitivism and selfregulated learning. Cognitive psychology is considered a new trend in contemporary psychology. It studies about the abilities and capabilities of human beings. This psychology adapts the environment and struggles to get perfection.

\section{Cognitive Psychology}

Cognitive Psychology deals with metal processes like thinking, memorizing, language acquisition, imagery, etc. This psychology also functions in creativity and problem solving skills. Cognitive psychologists believe that the human mind does not accept the exact forms and styles of the information from the environment. The conveyed information is compared with the information stored early in the mind. The information is analysed and stored in new forms. Those messages are interpreted and stored and taken to the need of the situation. Shuell and Sternberg say that cognitive approaches to learning give strain to learning. It is a process of active, constructive, cumulative and self-directed. Cognitive approach depends on the learners mental activities. It leads to the success of the learners. Active involvement of the learner is given a prominent role.

\section{Language and Human Brain}

There are two divisions in human brain. They are left hemisphere and right hemisphere. The left hemisphere is known as 'logical brain'. It involves in language learning and analysis. The right hemisphere is known as 'creative brain'. It involves in imagination and daydreaming. The right side of the body is controlled by left hemisphere and the left side of the body is controlled by right hemisphere. Physician noted that, if any injuries happen in left hemisphere the patient may lose their power of speech and language abilities. They do not lose their abilities, if the right hemisphere gets injured.

\section{Cognitive Factors}

Cognitive factor comprises the mental processes in language acquisition. It also explains the language knowledge of the learners. This factor analyses the learning mechanism of the brain. The computational model in cognitive approach includes three stages. During the first stage, the learners collect certain features in language and it is called input. This input is stored in short term memory. In second stage, the learner renovates the input into knowledge and store in long term memory. In the final stage, the stored knowledge is used as output. The learners use the knowledge for speaking the language with fluency, accuracy and coherence. In the second language acquisition, the mental process divides into micro-processes and macro-processes. Attention, restructuring, working memory are included in micro-processes. Restructuring is the processes of changing the inter language and monitoring the learners' conscious attention during output of the language. Macro-processes involves in distinction between intentional learning and incidental learning, explicit and implicit learning.

\section{Socio Cultural Factors}

Social aspects play an important role in second language acquisition. According to Ellis, there are three types of social structure which affect second language acquisition. The first type is sociolinguistic setting which involves in analysing the role of second language in the society. It also analyses how much the second language is influenced among the society. The second type is specific social factors affecting the second language acquisition. The factors include age, social class and ethnic identity. The third type is situational factors which analyse the social interaction. The learner may speak a standard language with higher social status, on the other side, they speak an informal way with their friends.

\section{Psychological Factors}

One can improve oneself in second language with regular practice of using the language. While practicing the second language, there may some psychological barriers. Anxieties, Shyness, Lack of confidence, Nervousness, Inferiority complex, etc., are some of the common factors affecting the learners in practicing the second language. The learner gets these common factors in learning a new language, because they do not acquire the language. They try to learn with the help of grammar rules. The learner can concentrate on acquiring the language by practicing before the audience and peer group. They can overcome these common factors by focusing on acquisition.

\section{Neurological Disorder Affecting the Second Language}

Neurological disorder is the main factor in language acquisition. Some important factors are discussed below.

\section{Dysgraphia}

Dysgraphia is a learning disability which affects written expression. The person having dysgraphia would have poor handwriting, troubled in spelling and trouble in writing their thoughts. They find difficulties in applying grammar rules and punctuation. There are many ways to tackle this disorder. Special 
accommodation in writing needs to be provided. The instructor can identify the area of weakness and train them based on it. The dysgraphia persons can improve their handwriting and writing skills with the help of special training.

\section{Dysprosody}

Dysprosody is also known as pseudo-foreign dialect, it is speech disorder. They can speak fairly but the rhythm of the speech gets disrupted which is rare among the population. Dysprosody is caused due to brain injury such as tumours or stroke damaging the brain, which controls the speech and language. This can be cured through regular practice and motivation.

\section{MERLD Disorder}

Mixed Receptive-expressive Language Disorder is a communication disorder. It affects both receptive and expressive area of communication. The child with this disorder finds striving in understanding words and sentences. This can be occurred dueto stroke or any head injury. This can be treated by giving special care and training.

\section{Pervasive Development Disorder}

It is the disorder, which affects the basic function of socialization and communication. The persons find difficulty in understanding language. They find difficulty in behaviors, emotions, anxiety and aggression. This can be cured by giving special training.

\section{Teaching Learning Practices}

Teachers play a main role in teaching field. They can produce new method to teach the learners. The teacher can bring out the best plan to teach them. They can follow the interactive teaching. The teacher can bring out the questionnaire with the help of a device to make teaching and learning. The learning environment should be supportive and productive. The students should be comfortable and the student should give new ideas by the learning process.

The teacher should motivate them to do their work autonomously. The teacher should encourage them for the team building skills which experience the sharing mentality, responsibility and ownership. Variety of teaching strategies should be followed to bring out the interest among the learners. Feedback practice can be done in the classroom. This method can be considered innovative and self-evaluating criteria.

\section{Conclusion}

There are theories and techniques to develop the second language. In order to achieve success in second language formal instruction, learning strategies, time and opportunity should go hand in hand to attain the goal. Time and opportunity are the main factors to get success. Moreover, motivation and guidance is the best psychological way to move on the track. Psychological encouragement may be given to the second language learners to tackle the situation. Learning classroom can be given to them to acquire the language naturally. Teachers play a main role in decreasing these psychological factors. They can help the students to perform better. The teacher can create friendly and informal learning environment to acquire the language.

\section{References}

[1] Abilasha R \& Ilankumaran M, "Trends in English Language Teaching: A Novel Perspective", International Journal on Studies in English Language and Literature (IJSELL), vol.2, no.11, (2014), pp.46-52.
[2] Annoussamy D, "Psychological Aspects of Language Acquisition", Journal of the Indian Academy of Applied Psychology, vol.32, no.2, (2006), pp.84-92.

[3] Broadbent DE, "Psychological Aspects of Short-Term and LongTerm Memory", Proceedings of the Royal Society of London. Series B, Biological Sciences, vol.175, no.1041, (2014), pp.333-350.

[4] Brown HD, Teaching by Principles, An Interactive Approach to Language Pedagogy, Englewood Cliffs: Prentice Hall Regents, (1994).

[5] Brown DV, "Cognitive Pruning and Second Language Acquisition", The Modern Language Journal, vol.56, no.4, (1972), pp.218-222.

[6] Gregg KRK, "Monitor and Occams Razor", Applied Linguistics, vol.5, no.2, (1984), pp.79-100.

[7] Hakes DT, "Psychological Aspects of Bilingualism", The Modern Language Journal, vol.49, no.4, (1965), pp.220-227.

[8] Isaac A, Technology of Teaching English, Vijaya Publishers, (2009).

[9] Kachru Y \& Smith LE. Cultures, contexts, and world Englishes, Routledge, (2008).

[10] Krashen SD, Second Language Acquisition and Second Language Learning, Prentice-Hall International, (1988).

[11] Priyanka SS \& Ilankumaran M, "Neurolinguistic Programme A Method or Myth", Journal of Language and Literature, vol.2, (2015), pp.50-51.

[12] Richards JC \& Theodore R, Edition Approaches and Methods in Language Teaching, New York: Cambridge University Press, (2001).

[13] Shull T, Cognitive Conceptions of Learning. Review of Educational Research, vol.56, no.4, (1986), pp.411-436.

[14] Sternberg R \& Anderson JR, Cognitive psychology and its implications, WH Freeman/Times Books/Henry Holt \& Co, (1996). 